\title{
Assessment of prescription completeness and antibiotic consumption at a rural health and training centre, Delhi
}

\author{
Arvind Kumar ${ }^{1 *}$, Arti Bahl², Sunil Gupta ${ }^{3}$, Charan Singh ${ }^{4}$, \\ Sudhir Kumar Jain ${ }^{5}$, Sujeet Kumar Singh ${ }^{6}$
} \author{
Puducherry, India \\ ${ }^{2}$ Division of Epidemiology, National Centre for Disease Control, Delhi, India \\ ${ }^{3}$ Division of Microbiology, National Centre for Disease Control, Delhi, India \\ ${ }^{4}$ Rural Health Training Centre, Najafgarh, Delhi, India \\ ${ }^{5}$ Division of Epidemiology, National Centre for Disease Control, Delhi, India \\ ${ }^{6}$ National Centre for Disease Control, Delhi, India
}

${ }^{1}$ Department of Preventive and Social Medicine, Jawaharlal Institute of Postgraduate Medical Education and Research,

Received: 01 July 2021

Accepted: 28 July 2021

\section{*Correspondence:}

Arvind Kumar,

Email: drarvind.ak@gmail.com

Copyright: (C) the author(s), publisher and licensee Medip Academy. This is an open-access article distributed under the terms of the Creative Commons Attribution Non-Commercial License, which permits unrestricted non-commercial use, distribution, and reproduction in any medium, provided the original work is properly cited.

\begin{abstract}
Background: The prescription audit is a useful method to assess the doctors' contribution to the rational use of drugs in a country. A prescription is considered complete when it covers all the parts of the prescription. The polypharmacy increased the risk of drug interaction, dispensing errors and confused the patients for dosage schedules. A prescription with the minimum number of drugs per prescription helps in rational pharmacotherapeutics. The objectives of this study were to describe the pattern and completeness of prescription at rural health and training center and to estimate antibiotic consumption at rural health and training center.

Methods: A descriptive cross-sectional study was conducted to determine the current prescribing practice at RHTC. Data were collected in the two pharmacies of the rural hospital. A total of 612 prescriptions with the last refill were considered for the assessment.

Results: The average number of drugs prescribed per prescription 3.53. The percentage of prescriptions in which an antibiotic was prescribed was $20 \%$. The percentage of drugs prescribed by generic name and from an essential drug list was $71.5 \%$ and $98.7 \%$ respectively. The most commonly prescribed form of antibiotics was extended-spectrum penicillin.

Conclusions: All the prescriptions were complete covered parts of prescriptions. The dosing errors were present in maximum prescriptions. The WHO prescribing indicators were within the limits, an average number of drugs per prescription suggests a practice of polypharmacy. The peak of the use of antibiotics was observed in September followed by January and November. The least use of antibiotics was in December followed by June.
\end{abstract}

Keywords: Antibiotic consumption, ATC/DDD, Polypharmacy, Prescription audit, Prescription practice

\section{INTRODUCTION}

A medical prescription comprises of the following parts; prescriber information, patient information, superscription, inscription, subscription, transcription or signa, and signature. ${ }^{1,2}$ The desired therapeutic outcome for each drug should be expressed when the drug is prescribed. Prescribers should review all the prescriptions for accuracy and legibility immediately after they have prescribed them. ${ }^{3}$ Globally, more than half of all medicines are not prescribed, dispensed, or sold properly as per guidelines, while half of the patients usually fail to take the 
drugs correctly as prescribed and one-third of the world population lacks access to essential medicines. ${ }^{4}$ The average number of drugs per prescription is going up to 7.4 per visit to the health facility. ${ }^{5}$ This number is much higher than the WHO recommended limit of 1.6 to 1.8 . This inappropriate practice should be minimized by reducing the number of drugs per prescription and this can help in rational pharmacotherapeutics. Usually, drugs are prescribed by their generic names in the range from $0.05 \%$ to $89.8 \%$ per encounter as against the standard of $100 \%$.,7 In most of the developing countries, $15-25 \%$ of prescriptions with antibiotics are expected where the prevalence of infectious diseases is from $34.4 \%$ to $50 \% .^{8,9}$ Appropriate use of antibiotics is necessary to prevent the emergence of drug resistance and antibiotics should preferably be prescribed after culture sensitivity testing. Polypharmacy is a very common practice nowadays as reported by various studies. ${ }^{10}$ It is of concern in patients with various co-morbidities as it increases the chances of drug interactions and adverse effects. The study reported $62.4 \%$ of prescriptions had three or more drugs prescribed which increases the risk of drug interactions, dispensing errors, and the parent/caregiver not knowing the dosage schedules. ${ }^{11}$ In April 2013, WHO had released the 18th model essential drug list containing 353 formulations and 26 fixed-dose combinations (FDC's), and the National List of Essential Medicines (NLEM) of India has 348 essential drugs, including 16 fixed-dose combinations. ${ }^{12,13}$ The copy of EDL is available at centers and the percentage of key drugs available was $88 \% .{ }^{14}$ Rational drug use is possible only to follow the good prescribing practice. A prescription audit, therefore, is a useful method to assess the doctors' contribution to the rational use of drugs in a country. There was limited data available about inappropriate prescription practices such as polypharmacy and consumption of antibiotics in the present and similar settings. The objectives of this study were aimed to describe the pattern and completeness of prescription at rural health and training center and to estimate antibiotic consumption at rural health and training center in a calendar year.

\section{METHODS}

\section{Study design}

The present study was a prospective cross-sectional descriptive study.

\section{Study setting}

\section{General setting}

The present study was conducted at the Rural Health Training Center (RHTC) at Najafgarh, New Delhi. As of the 2011 India census, Najafgarh block was the most populous block under the southwest district of Delhi with a population of 1,365,152. ${ }^{15}$ RHTC Najafgarh has been providing health services to the low socio-economic group of people of 39 villages and 11 towns of Najafgarh through its three primary health centres and 16 sub-centres including 24×7 emergency services in PHC, Najafgarh.

\section{Specific setting}

The training center is a subordinate office of the Directorate General of Health Services, Ministry of Health and Family Welfare, Government of India. The RHTC, Najafgarh was set up as a health unit in 1937 and evolved for the next 50 years to become a national scientific institute. Several training activities are going on RHTC, Najafgarh i.e.; training of Medical Interns under Reorientation of Medical Education (ROME) scheme; training of ANM students with an intake capacity of 40 students per academic session and Community Health Nursing training to $\mathrm{BSc} / \mathrm{MSc} / \mathrm{GNM}$ students of various Nursing institutions like College of Nursing, Safdarjung Hospital, RML Hospital, Lady Hardinge Medical College, Holy Family Hospital, Batra Hospital, Apollo Hospital, and various other Govt./State Govt./Private institutions. The center conducts field studies aspects of Health and Family Welfare, Reproductive and Child Health, Nutrition, Health Education, and Communicable Diseases and also provides field services for research work to the various health institutions like the National Institute of Health and Family Welfare (NIHFW) and All India Institute of Medical Sciences in public health (AIIMS) in public health. OPD load per day is around 1000 patients.

\section{Study participants}

For the present study, prescriptions of patients attending the RHTC were considered. According to the WHO document "How to investigate drug use in health facilities," at least 600 encounters should be included in a cross-sectional survey to describe the current prescribing practices, with a greater number, if possible. Following the WHO guidelines and the time constraint, the sample size was 612 prescriptions.

\section{Inclusion criteria}

\section{Prescription audit}

The daily OPD prescription was included in the study. In the case of multiple refill orders, the latest refill was considered for the assessment of the prescription.

\section{Antibiotic consumption}

The antibiotics consumption in a year was included for tablets and capsules only.

\section{Exclusion criteria}

\section{Prescription audit}

The prescription of the referred and admissible patients were excluded from the study. 


\section{Antibiotic consumption}

Antibiotics for local use, like creams and drops, were not included in calculating the DDDs consumed.

\section{Data variables, sources of data, and data collection}

\section{Prescription audit}

The study was carried out prospectively for two months (January and February 2018). Data was collected from the pharmacy in the compound of RHTC after the medicines were dispensed. The patient interview was not conducted and only information like patients' profiles (identifiers like name, the address was not taken), parts of prescription, drug details, and dosing errors were recorded for assessment of prescription.

The prescription data were collected five days a week amid OPD working hours i.e.; between 9 am to 1 pm using a pretested structured questionnaire. The data collection proforma was prepared based on WHO guidelines about the investigation of drug use in a health facility, the Medical Council of India's format of a prescription order, and literature search.

\section{Antibiotic consumption}

The antibiotic consumption data from January 2016 to December 2016 were extracted from the purchase bills (records) maintained by the facility and collected on a proforma, designed to contain the names of all antibiotics, the different strengths available, and the quantity procured for each antibiotic. Consumption of antibiotics was calculated using the WHO ATC-DDD tool and presented in terms of DDDs per 1000 population per day for the facility.

\section{Data entry and statistical analysis}

\section{Prescription audit}

Double data was entered and validated to ensure the quality on EpiData version 3.1 and analyzed using EpiData analysis V2.2.2.182 (EpiData Association, Odense, Denmark). The continuous variable was expressed as mean (SD) and the categorical variable was expressed as frequency and percentage.

\section{Antibiotic consumption}

AMC tool version 1.9.0 was used for data entry and calculation of antibiotic consumption from packages data into Defined Daily Doses (DDD). Indicator DDD per 1000 inhabitants per day (DID for consumption in the community) generated by AMC tool. Ethics approval was obtained from the National Centre of Disease Control Ethics Review Committee, Delhi, India. Identifiers such as the name and address of the patient and the name and address of the prescribing doctor were not recorded.

\section{RESULTS}

\section{Prescription audit}

A total of 612 prescriptions were analyzed. The median (IQR) age of patients was 25.5 (15-42) years. Out of the total, $58.3 \%$ of prescriptions analyzed from the OPD during the study period were of male patients. Most of the prescriptions $(91.7 \%)$ belonged to patients who came the first time in OPD. The prescriptions generated in general, pediatrics and orthopedic OPDs were $41.8 \%, 22.7 \%$, and $19.1 \%$ respectively, other prescriptions generated were from chest clinic, ophthalmology, etc.

\section{Pattern and completeness of prescription}

The date of the prescription writing was mentioned in $98.7 \%$ of the prescriptions. The inscription including name, concentration, and type of medicine was written in $92.0 \%, 48.5 \%$, and $93.1 \%$ respectively. The subscription part of the prescription including the direction to the dispenser and the patients was observed in $62.6 \%$ and $82.7 \%$ respectively. The signature with the date of the prescriber was mentioned in $69.9 \%$ and $12.8 \%$ respectively (Table 1). Other important information like name, age, the address was observed in $99.8 \%, 99.2 \%$, and $0.5 \%$ respectively. Only $0.3 \%$ of prescriptions had mention of a history of drug allergy. Follow-up advice to the patients was not mentioned in $97.4 \%$ of the prescriptions. None of the prescriptions had any diagnosis (probable, differential, or confirmed) mentioned on them. Table 2 describes dosing errors in prescription writing. The interval between doses was mentioned in $35.6 \%$ of the prescriptions. The other important information like the route of drug administration, warning for medication, nonpharmacological measures, follow-up date, and errors of formulation of drugs were almost nil. The comparison between WHO core prescribing indicators and the findings of our study is depicted in Table 3. The average number of drugs per prescription was double that of the WHO standards. The percentage of antibiotics and drugs prescribed from the essential list was close to the WHO standards.

\section{Drug profile of the prescriptions at RHTC}

Antibiotics were prescribed nearly in one-fifth of the prescriptions $(19.9 \%)$. Nearly two-thirds $(71.5 \%)$ of the medicines as prescribed by generic name. Fixed-dose combinations were prescribed in $28.1 \%$ of prescriptions. Most of the medicines were prescribed from the essential drug list (98.7\%). The analgesic, multivitamins, and FDCs were prescribed in $52.3 \%, 37.1 \%$, and $28.1 \%$ of the prescription respectively. A total of 2160 drug products and an average (mean \pm SD) 3.5 \pm 1.6 medicines were prescribed per prescription. Out of that, the average 1.3 medicines per prescription was with a generic name. Most of the prescriptions (82.4\%) had 2-5 medicines per prescription. Most of the antibiotics (60.6\%) were prescribed for 3-5 days. 
Table 1: Distributions of completeness of parts of prescriptions at Rural Health Training Centre, Najafgarh, Delhi (N=612).

Parts of prescription

Date on the prescription mentioned

Appropriate Name of medicine mentioned

Appropriate concentration/strength mentioned

Type of medicine (tablet, capsule, etc.) mentioned

Abbreviation of medicine mentioned

Instruction to the pharmacist (No. of capsules/tablets and size of bottle) mentioned

Instruction to the patient mentioned

Follow up advice to the patients mentioned

Use of Latin abbreviation

Doctors signature present

Date below signature
Frequency $(\%)$

$604(98.7)$

$563(92.0)$

$297(48.5)$

$570(93.1)$

$75(12.3)$

$383(62.6)$

$506(82.7)$

$16(2.6)$

$466(76.1)$

$428(69.9)$

$78(12.8)$

Table 2: Dosing/therapeutics errors in prescription writing at Rural Health Training Centre, Najafgarh, Delhi $(\mathrm{N}=612)$.

\section{Characteristics}

Route of administration mentioned in the prescription

The interval between doses mentioned

Instructions/warning for medication use mentioned

Non-pharmacological measure mentioned

Follow update mentioned

Wrong strength present

An error of formulation of a drug (tablet instead of syrup injection or vice versa)
Frequency $(\%)$

$29(4.7)$

$218(35.6)$

$7(1.1)$

$20(3.3)$

$8(1.3)$

$11(1.8)$

$4(0.7)$

Table 3: Comparison of WHO core prescribing indicators between the study result and WHO standard (N=612).

\begin{tabular}{|c|c|c|}
\hline WHO indicators & Findings & WHO standard \\
\hline The average number of drugs per prescription & 3.53 & $1.6-1.8$ \\
\hline Percentage of drugs prescribed by generic name & $71.5 \%$ & $100 \%$ \\
\hline Percentage of prescription with an antibiotic prescribed & $19.9 \%$ & $20.0-26.8 \%$ \\
\hline Percentage of prescription with an injection prescribed & $2.9 \%$ & $13.4-24.1 \%$ \\
\hline Percentage of drugs prescribed from essential drug list & $98.7 \%$ & $100 \%$ \\
\hline
\end{tabular}

Note: Average one generic medicine per prescription.

\section{Antibiotic consumption}

The distribution of antibiotics based on ATC classification and DDD per 1000 population per day (DID) is given in Table 4. The antibiotics prescribed for systemic use by the RHTC were mainly beta-lactam and macrolides. Among the antibiotics used, beta-lactam antibiotics with enzyme inhibitors were most $(89.3 \%)$ commonly used. Figure 1 shows maximum consumption of antibiotics was in September followed by January and November. December and June were the lowest in the consumption pattern. Figure 2 shows the proportion consumption of the different formulations. Ampicillin with cloxacillin and augmentin was the most commonly used formulation.

Table 4: Distribution of antibiotics consumption based on ATC classification prescribed at Rural Health Training Centre, Najafgarh, Delhi in a calendar year.

\begin{tabular}{|lllll|}
\hline Antibiotics & ATC code & DDD & Proportion of all DDD (\%) & DDD/1000 population/day \\
\hline Ampicillin & J01CA01 & 4000 & 3.6 & 0.03652968 \\
\hline Amoxicillin & J01CA02 & 5641 & 5.0 & 0.051515982 \\
\hline $\begin{array}{l}\text { Amoxicillin and enzyme } \\
\text { inhibitor }\end{array}$ & J01CR02 & 100229.7 & 89.3 & 0.915340155 \\
\hline $\begin{array}{l}\text { Azithromycin } \\
\text { Antibacterial for systemic } \\
\text { use }\end{array}$ & J01FA10 & 2371.5 & 2.1 & 0.021657534 \\
\hline
\end{tabular}




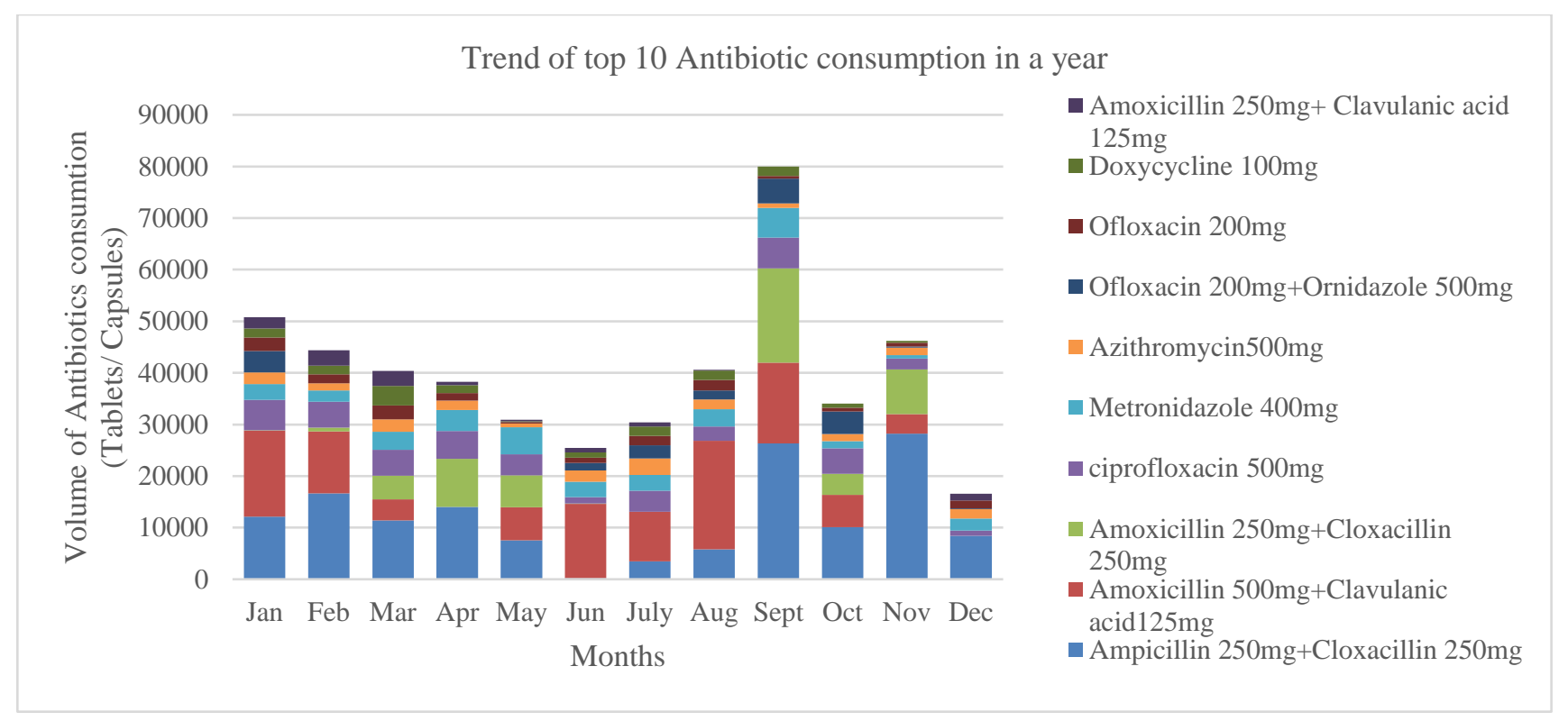

Figure 1: Top 10 antibiotics consumption trend.

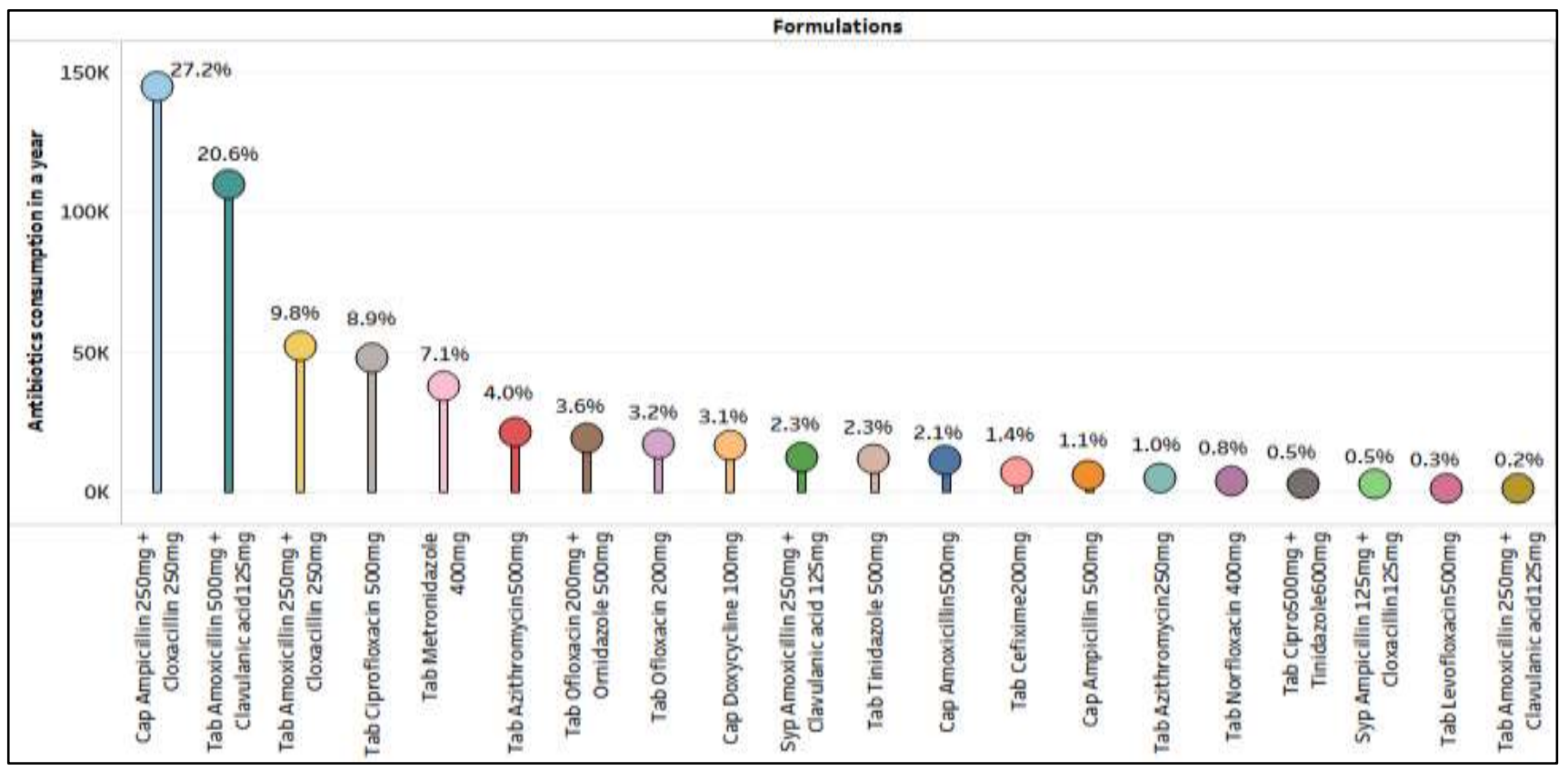

Figure 2: Percentage of the antibiotic's consumption in a year.

\section{DISCUSSION}

The present study was conducted to focus on the completeness of prescription and pattern of antibiotics use at the rural health training center. The prescriptions were in printed form with the details of RHTC. The anatomy of prescriptions consists of several important parts includes; date and information about patients, superscription, inscription, subscription, signa, and signature. The RHTC is a training center for undergraduate medical interns and this kind of negligence in practice may affect the quality of future medical practitioners. Some interesting findings in the study are discussed below. The basic information of the patient like name and age and date of the prescription was observed in almost all of the prescriptions. This was also observed in a study conducted by Sharif et.al in Dubai. ${ }^{16}$ The address of the patient, diagnosis, and history of allergy was almost nil. Similar findings were also noticed in other studies conducted in Jammu, rural medical college in Maharashtra, and Ranchi. ${ }^{17-19}$ The address is important to understand the pattern of disease in a specific area. Without a diagnosis, on prescription, it will be difficult to understand the treatment for a specific disease. Sharif et.al also noticed a similar observation. ${ }^{16}$

The important information like date, appropriate name of medicines, and type of medicine was mentioned in almost all the prescriptions (>90\%). Instruction to the pharmacist, 
to the patients, and prescribers' signatures were used in $63 \%, 83 \%$, and $70 \%$ respectively. In contrary to our findings, Saurabh et al found opposite results in a study, conducted at a primary health center, Jhalawar, Rajasthan. This could be because RHTC is a training center and the interns are working closely with a regular staff of the rural hospital. ${ }^{17}$ Follow-up advice was almost absent from the prescription.

Dose-related errors, route of administration, warning for medication, non-pharmacological measures, and followup data were absent in almost all the prescriptions. The prescribers were well aware of errors of formulation and wrong strength, but instruction mentioning intervals between doses found in $37 \%$ of the prescriptions. These observations coincide with the finding of Kaur et al in Ambala, Haryana. ${ }^{20}$ Saghafi et al in Isfahan, Iran also observed similar results, where more than two-thirds of prescriptions had errors. ${ }^{21}$

The average number of drugs prescribed in the present study was 3.53 , which is double the WHO standards and indicates the practice of polypharmacy. The studies from different parts of India suggest the average number of drugs per prescription was from 2.2 to $8.8 .^{18,20,22-24}$ This indicates that polypharmacy is quite common in India. It is recommended to prescribe the drugs by a generic name instead of the proprietary name, the present study indicates the $71.5 \%$ of the drugs were prescribed by a generic name. Other studies from different parts of India also support our finding of prescribing medicine with generic name. ${ }^{7,24-26}$ But, some studies show that practicing generic medicine is not common and the proportion of generic medicine practice was observed in up to $25 \%$ of the prescriptions. ${ }^{6,20,27}$

The prescriptions with antibiotics were within the limit of standards recommended by WHO and this was also observed in studies from urban and rural health centers across India. ${ }^{18,22-24,28}$ There were few prescriptions with injections. In other studies also, the practice of prescribing injectables in OPD is low and within the range of the WHO standards. ${ }^{18,19,21,22,25}$ The prescription from the essential drug list indicator was following the standard recommended by WHO. There are some studies reported similar finding whereas studies from the tertiary hospital reported half of the prescription were from EDL and less than 50\% also. ${ }^{6,20,27}$ Analgesics (NSAIDs) and multivitamins were the most commonly prescribed medicines. Among the antibiotics, extended-spectrum penicillin was prescribed most frequently. The tendency of prescribing analgesics, vitamins, and extended-spectrum penicillin is also common in other studies also. ${ }^{16,23,25}$ The measurement units assigned to the data were according to the ATC classification and the DDD. Extended-spectrum penicillin was more consumed than other antibiotics at the rural health training facility. The more frequent usages of extended-spectrum penicillin over other antibiotics are also suggested from studies on pharmacy records in Delhi,
India, and from the secondary level hospital in the United Kingdom and Lebanon. ${ }^{29-31}$

\section{CONCLUSION}

Writing diagnosis, follow-up advice, doses, nonpharmacological instruction, and date of the signature by prescriber was not common. The proportion of the antibiotics and all medicines were mostly from the essential drug list of the center. The DID of the extendedspectrum penicillin and proportion was higher than the other medicines. The study explained the prescription practice and antibiotic consumption at the peripheral training center. The sample size of auditing of the prescription was following WHO standard and DID calculate by authentic AMC tool. The interns were working under different faculty and we couldn't identify the prescription written by them exclusively. The study was limited to a public sector rural health training center and the result may differ from secondary or tertiary health centers as well as an inpatient. The study highlighted the poor or deficient prescription writing practice. There is a need for capacity building of the interns and staff to improve the quality of prescription writing. There is a need to analyze the antibiotics consumption with microbiological data to identify the sensitivity of the medicine.

\section{ACKNOWLEDGEMENTS}

We thank all the pharmacists, and hospitals in charge of the Rural Health Training Center and patients for their cooperation and support during the study.

Funding: No funding sources

Conflict of interest: None declared

Ethical approval: The study was approved by the Institutional Ethics Committee

\section{REFERENCES}

1. Brunton L, Chabner BA, Knollman B. Goodman and Gilman's the Pharmacological Basis of Therapeutic. 12th ed. New York, NY: McGraw Hill; 2011.

2. Indian Medical Council. Professional Conduct, Etiquette and Ethics, 2002. Available at: https://www.mciindia.org/documents/rulesAndRegul ations/Ethics Regulations-2002. Accessed on 20 June 2021.

3. American Society of Hospital Pharmacists. ASHP Guidelines on Preventing Medication Errors in Hospitals. American J Hospital Pharm. 1993;50(2):305-14.

4. WHO. WHO Policy Perspectives on MedicinesPromoting Rational Use of Medicines: Core Components WHO Policy Perspectives on Medicines, 2002. Available at: http://www.msh.org/. Accessed on 20 June 2021. 
5. Devi DP, George J. Diabetic nephropathy: prescription trends in tertiary care. Indian J Pharm Sci. 2008;70(3):374-8.

6. Mishra S, Sharma P. Prescription audit and drug utilization pattern in a tertiary care teaching hospital in Bhopal. Int J Basic Clin Pharmacol. 2016;5(5):18459.

7. Pathak A, Gupta VK, Maurya A, Kumar A, Singh A. Assessment of drug prescribing pattern using WHO indicators in hospitalized patients at a tertiary care teaching hospital in rural area of India. Int J Basic Clin Pharmacol. 2016;5(3):651-5.

8. Gupta A, Mishra S. Prescription audit study in a tertiary care hospital using the anatomical therapeutic chemical and defined daily dose classification concept. Int J Basic Clin Pharmacol. 2014;3(5):889.

9. Tamuno I, Fadare JO. Drug Prescription Pattern in a Nigerian Tertiary Hospital. Trop J Pharm Res. 2012;11(1):146-52.

10. Mittal N, Mittal R, Singh I, Shafiq N, Malhotra S. Drug utilisation study in a tertiary care center: recommendations for improving hospital drug dispensing policies. Indian J Pharm Sci. 2014;76(4):308-14.

11. Karande S, Sankhe P, Kulkarni M. Patterns of prescription and drug dispensing. Indian $\mathrm{J}$ Pediatr. 2005;72(2):117-21.

12. WHO. WHO Model List of Essential Medicines 19th List, 2015. Available at: http://www.who.int/medicines/publications/essential medicines/en/. Accessed on 20 June 2021.

13. Central Drugs Standard Control Organization. National List of Essential Medicines (NLEM), 2015. Available at: http://cdsco.nic.in/WriteReadData/NLEM2015/NLE M, 2015.pdf. Accessed on 20 June 2021.

14. Prasad PS, Rudra JT, Vasanthi P, Sushitha U, Sadiq MJ, Narayana G. Assessment of drug use pattern using World Health Organization core drug use indicators at Secondary Care Referral Hospital of South India. Chrismed J Heal Res. 2015;2(3):223-8.

15. Directorate of Census Operations. District Census Handbook, Census of India 2011; Series-08; Part XIIA, 2011. Available at: https://censusindia.gov.in/2011census/dchb/0700_PA RT_A_DCHB_NCT OF DELHI.pdf. Accessed on 20 June 2021.

16. Sharif S, Shaqra M, Hajjar H, Shamout A, Wess L. Patterns of drug prescribing in a hospital in dubai, United arab emirates. Libyan J Med. 2008;3(1):10-2.

17. Sharma P, Kapoor B. Study of prescribing pattern for rational drug therapy. JK Sci. 2003;5(3):5-7.

18. Kumari S, Haider S, Kashyap V, Singh SB. a Study on Pattern of Prescription Writing Practices At Rajendra Institute of Medical Sciences, Ranchi. Indian J Prev Soc Med. 2014;45(1):101.

19. Phalke VD, Phalke DB, Aarif SMM, Mishra A, Sikchi $S$, Kalakoti P. Prescription writing practices in a rural tertiary care hospital in Western Maharashtra, India. Australas Med J. 2011;4(1):4-8.

20. Kaur B, Walia R. Prescription Audit for evaluation of prescribing pattern of the doctors for rational drug therapy in a tertiary care hospital. J drug Deliv Ther. 2013;3(5):77-80.

21. Saghafi, F ZA. Medication error detection in two major teaching hospitals: What are the types of errors?. J Res Med Sci. 2014;19(7):617-23.

22. Aravamuthan A, Arputhavanan M, Subramaniam K, Udaya CJSJ. Assessment of current prescribing practices using World Health Organization core drug use and complementary indicators in selected rural community pharmacies in Southern India. J Pharm Policy Pract. 2016;10(1):1.

23. Kumar MS, Kumar NB, AY, Ashish S, Avinash S. Study of prescribing habits and assessment of rational use of drugs among doctors of primary health care facilities. Asian J Pharm Clin Res. 2011;4(4):102-5.

24. Sudarsan M, Sitikantha B, Aparajita D. Audit and Quality Assessment of Prescriptions in an Urban Health Centre of Kolkata. Int J Med Public Heal. 2016;6(3):136-9.

25. Potharaju H, Kabra S. Prescription audit of outpatient attendees of secondary level government hospitals in Maharashtra. Indian J Pharmacol. 2011;43(2):150-6.

26. Sumalatha R, Nagabushan H. Assessment of knowledge, attitude and practice of prescription writing as per Medical Council of India guidelines among interns in a Medical College. Int J Pharmacol Res. 2016;6.

27. Abidi A, Gupta S, Kansal S. Prescription auditing and drug utilization pattern in a tertiary care teaching hospital of western UP. Int J Basic Clin Pharmacol. 2012;1(3):184-90.

28. Shelat PR, Kumbar SK. Analysis of out door Patients' prescriptions according to World Health Organization (WHO) prescribing indicators among private hospitals in Western India. J Clin Diagnostic Res. 2015;9(3):14.

29. Kotwani A, Holloway K. Trends in antibiotic use among outpatients in New Delhi, India. BMC Infect Dis. 2011;11(1):99.

30. Berrington A. Antimicrobial prescribing in hospitals: be careful what you measure. J Antimicrob Chemother. 2010;65(1):163-8.

31. Iskandar K, Hanna PA, Salameh P, Raad EB. Antibiotic consumption in non-teaching Lebanese hospitals: A cross-sectional study. J Infect Public Health. 2016;9(5):618-25.

Cite this article as: Kumar A, Bahl A, Gupta S, Singh C, Jain SK, Singh SK. Assessment of prescription completeness and antibiotic consumption at a rural health and training centre, Delhi. Int J Basic Clin Pharmacol 2021;10:1114-20. 